\title{
Evaluation of Glycine max Germ Plasm for Resistance to Fusarium solani f. sp. glycines
}

\author{
D. S. Mueller, Department of Crop Sciences, G. L. Hartman and R. L. Nelson, USDA/Agricultural Research Ser- \\ vice, Soybean/Maize Germplasm, Pathology, and Genetics Research Unit and Department of Crop Sciences, and \\ W. L. Pedersen, Department of Crop Sciences, University of Illinois, Urbana 61801
}

\begin{abstract}
Mueller, D. S., Hartman, G. L., Nelson, R. L., and Pedersen, W. L. 2002. Evaluation of Glycine max germ plasm for resistance to Fusarium solani f. sp. glycines. Plant Dis. 86:741-746.

Sudden death syndrome, caused by Fusarium solani f. sp. glycines, has caused increased losses in soybean production in recent years. This study was done to identify potential sources of resistance to sudden death syndrome. Using a greenhouse screening procedure, 6,037 soybean plant introductions (PIs) were compared with a susceptible check, Great Lakes 3302, and two moderately resistant checks, PI 520.733 and PI 567.374, for resistance to sudden death syndrome. Only 57 PIs had foliar disease ratings that were not significantly different from PI $567.374(P \leq$ 0.05) 3 weeks after inoculation. Six PIs had lower ratings than PI 567.374 at 4 weeks after inoculation, while none had lower area under the disease progress curve (AUDPC) values. When comparing the PIs to PI 520.733, 209 PIs had foliar disease ratings not significantly different from PI $520.733(P \leq 0.05) 3$ weeks after inoculation. Eight PIs had significantly lower disease severity ratings 4 weeks after inoculation, and 38 PIs had significantly lower AUDPC values than PI 520.733. Additionally, root lesion lengths were measured 4 weeks after inoculation and ranged from 25.2 to $41.5 \mathrm{~mm}$ for all the PIs; none of the entries had smaller lesion lengths than the susceptible check Great Lakes 3302. The correlation between lesion length and disease foliar severity rating was not significant. There also were no plant morphological characteristics (i.e., flower color or seed coat color) associated with higher sudden death syndrome foliar symptoms. Eighteen PIs previously identified as moderately resistant with differing agronomic traits were inoculated with five different isolates of Fusarium solani f. sp. glycines. Results indicated that resistance in these 18 PIs was effective against all five isolates of Fusarium solani f. sp. glycines. Isolate Mont-1 caused the greatest disease severity ratings. These PIs that exhibited low foliar severity ratings may provide new sources of resistance for the development of new sudden death syndrome-resistant lines and cultivars.
\end{abstract}

Sudden death syndrome of soybean (Glycine max (L.) Merr.) is caused by the soilborne fungus Fusarium solani (Mart.) Sacc. f. sp. glycines (23). Sudden death syndrome now has been identified in most soybean producing regions of the United States $(11,24,30)$. Doupnik reported sudden death syndrome as being an important soybean disease in the north-central region of the United States from 1989 to 1991 (8). In 1994, sudden death syndrome was listed as one of the major soybean diseases for the top 10 soybean production areas in the world (29).

Sudden death syndrome foliar symptoms usually develop shortly after the onset of

Corresponding author: W. L. Pedersen

E-mail: wpederse@uiuc.edu

Trade and manufacturer's names are necessary to report factually on available data; however, the USDA neither guarantees nor warrants the standard of the product, and the use of the name by USDA implies no approval of the product to the exclusion of others that may also be suitable.

Accepted for publication 19 February 2002.

Publication no. D-2002-0429-03R

(C) 2002 The American Phytopathological Society crop flowering. The most characteristic symptoms occur on the leaves. These include mottling, mosaic, interveinal chlorosis and necrosis on the upper leaves, defoliation, and frequently premature plant death. Other symptoms include root rot, crown rot, vascular discoloration of stems, and pod abortion $(24,26)$.

Resistance to $F$. solani $\mathrm{f}$. sp. glycines has been reported in both field and greenhouse experiments. However, most modern cultivars are still considered susceptible to sudden death syndrome (Varietal Information Program for Soybeans [VIPS] website, University of Illinois, Urbana). Identifying new sources of resistance in the USDA Soybean Germplasm Collection may improve resistance to $F$. solani f. sp. glycines of modern soybean cultivars. Currently, the USDA Soybean Germplasm Collection has 16,593 introduced G. $\max$ accessions. A previous study (10) involving growth chamber and greenhouse tests evaluated 728 plant introductions (PIs) for resistance to F. solani $\mathrm{f}$. sp. glycines and identified PI 567.374, PI 567.315, PI 567.441C, PI 567.650B, and PI 567.664 as being moderately resistant to sudden death syndrome.

$F$. solani f. sp. glycines isolates vary in their ability to cause disease $(13,14,16,25)$.
One preliminary report suggested that races of $F$. solani $\mathrm{f}$. sp. glycines may exist (17). Since this report, however, there has been no follow-up research to confirm or refute the existence of races in $F$. solani $\mathrm{f}$. sp. glycines (24).

The objectives of this study were to identify plant introductions from the USDA Soybean Germplasm Collection with resistance to $F$. solani f. sp. glycines and to determine if a select set of moderately resistant PIs was effective against several isolates of $F$. solani $\mathrm{f}$. sp. glycines.

\section{MATERIALS AND METHODS}

Plant introductions. A total of 6,037 PIs from the USDA Soybean Germplasm Collection, Urbana, IL, were inoculated with $F$. solani f. sp. glycines in the greenhouse. The set of PIs originated from 38 countries, with the majority coming from China (2,077 PIs), South Korea (1,947 PIs), and Japan (1,335 PIs) (Table 1). All the PIs were in maturity group II $(1,647$ PIs), III (1,442 PIs), or IV (2,946 PIs). Included with each entry was a description of several plant morphological characteristics (i.e., determinate and indeterminate, flower color, pubescence color or density, pod color, seed coat luster, and seed coat color).

Inoculum increase. Inoculum of $F$. solani f. sp. glycines was prepared by soaking $200 \mathrm{~cm}^{3}$ of sorghum grain in distilled water in a 1-liter Erlenmeyer flask overnight (10). Excess water was drained and the grain autoclaved for $60 \mathrm{~min}$ at $121^{\circ} \mathrm{C}$ on consecutive days and allowed to cool. After cooling, 10 plugs, $6 \mathrm{~mm}$ diameter, containing mycelia of $F$. solani f. sp. glycines isolate Mont-1 (P. Stevens, Illinois) (9) on water agar were added to the flask. The flask was shaken daily and incubated at $24^{\circ} \mathrm{C}$ under continuous fluorescent light $\left(60 \mu \mathrm{E} \cdot \mathrm{m}^{-2} \cdot \mathrm{s}^{-1}\right)$. After 10 days of growth, inoculum was stored at $4^{\circ} \mathrm{C}$.

Inoculation and plant husbandry. Four liters of a greenhouse steam-treated soil mix (1:1 sand/soil) was placed in $50 \times$ $35 \times 10 \mathrm{~cm}$ galvanized flats. A template was used to make seven furrows $2 \mathrm{~cm}$ deep and $35 \mathrm{~cm}$ long, and $10 \mathrm{~cm}^{3}$ of infested sorghum seed was evenly distributed in each furrow. The inoculum was then covered with $2 \mathrm{~cm}$ of soil, and the template was reapplied to make a $0.5-\mathrm{cm}$-deep furrow directly over the inoculum. Seed of PIs and check varieties was added to each 
furrow and covered with another $2 \mathrm{~cm}$ of soil. Plants were then placed on a greenhouse bench and grown under a 16-h photoperiod. The photosynthetically active radiation was $434 \mu \mathrm{E} \cdot \mathrm{m}^{-2} \cdot \mathrm{s}^{-1}$. Room mean temperature was $25.5^{\circ} \mathrm{C}$, with a range of 23.9 to $27.8^{\circ} \mathrm{C}$. Plants were watered to saturation after planting and maintained at near field capacity throughout the study.

Disease ratings. Two to 4 weeks after inoculation, plants were rated for sudden death syndrome foliar symptoms on four separate dates. Plots were rated if two or more seeds emerged. Unless otherwise stated, an assessment of the whole plot was made using disease ratings based on a 1 to 9 scale: $1=$ no symptoms; 2 to $4=$ light symptom development (1 to 5\%, 5 to $10 \%$, and 10 to $20 \%$ foliage affected); 5 and $6=$ moderate symptom development (20 to $35 \%$ and 35 to $50 \%$ foliage affected); 7 and 8 = heavy symptom development (50 to $65 \%$ and 65 to $80 \%$ foliage affected); and 9 $=$ severe symptom development $(81$ to $100 \%$ foliage affected). In all replicated experiments, disease severity ratings were converted to percent midpoint values (5). Area under the disease progress curve (AUDPC) values were calculated (28) based on the midpoints.

Greenhouse experiment. For all experiments, five seeds per entry (i.e., PI) were planted in flats containing 20 entries and one check. The susceptible (S) check was Great Lakes 3302 (GL3302), and the moderately resistant (MR) checks were PI 520.733 and PI 567.374 (10). The entire set was screened in nonreplicated subsets of 500 PIs. Entries that had a mean disease severity rating and an AUDPC value 1.0 standard deviation below the mean of the subset or were not significantly different from either of the MR checks were advanced to the second stage. The second stage (1,302 entries from stage one) was planted as a nonreplicated set. The entries that had a mean disease severity rating and an AUDPC value 1.0 standard deviation below the mean of the set were advanced to the third stage. For the third stage, 212 accessions from stage two were arranged in a randomized complete block (RCB) design with four replications. Of these 212 entries, 57 were repeated in the final stage. These 57 PIs had foliar symptoms that were not significantly different from $(P \leq$ 0.05) the MR check PI 567.374 in the third stage. In the final stage, foliar ratings were taken 14, 17, 20, and 23 days after plants were inoculated. Additionally, 7 days after the fourth rating (30 days after planting), each plant was rated individually for severity of foliar symptoms and the ratings averaged. Soil was washed from five plants and two replications (10 plants total), and the lesion length $(\mathrm{mm})$ on the taproot was measured.

Isolate study. Five isolates of $F$. solani f. sp. glycines collected from soybean: (i) Mont-1, (ii) FSA-1 (J. Rupe, Arkansas), (iii) In (S. Abney, Indiana), (iv) BH-F2-13
(X. Yang, Iowa), and (v) 98-7 (S. Li, Illinois), were selected for this study based on their geographical diversity. All isolates were maintained at $19^{\circ} \mathrm{C}$ on slants of Bilay's medium (4). Using the greenhouse screen described previously, 18 entries previously identified as being moderately resistant were evaluated for severity of foliar symptoms after inoculation with the five isolates. Ratings on foliar symptoms were taken 2 to 4 weeks after inoculation. Four weeks after inoculation, 8 to 10 plant roots of each PI were washed free of soil and root lesion length was determined. The experiment was arranged in an RCB design with four replications and was done in two different greenhouse environments. The first environment had a mean room temperature of $25.5^{\circ} \mathrm{C}$, while the second environment had mean room temperature of $23.5^{\circ} \mathrm{C}$.

Data analysis. For all replicated experiments, data were subjected to analysis of variance using general linear models procedure (PROC GLM) of SAS (SAS Institute, Cary, NC). Trials and replications were considered random variables, while soybean lines were considered a fixed variable. Means were separated by Fisher's protected least significant differences (LSD) at $P \leq 0.05$. Mean foliar disease ratings for entries differing in morphological characteristics were calculated for the 12 nonreplicated subsets and compared in single-degree-of-freedom contrasts.

Table 1. Country and province of origin of soybean entries screened for resistance to Fusarium solani f. sp. glycines from the USDA Soybean Germplasm Collection

\begin{tabular}{|c|c|c|c|c|c|c|c|}
\hline Country & $\begin{array}{l}\text { No. of } \\
\text { entries }\end{array}$ & Country & $\begin{array}{l}\text { No. of } \\
\text { entries }\end{array}$ & Country & $\begin{array}{l}\text { No. of } \\
\text { entries }\end{array}$ & Country & $\begin{array}{l}\text { No. of } \\
\text { entries }\end{array}$ \\
\hline China & 2,077 & Korea, South (con.) & & Japan (con.) & & Korea & 17 \\
\hline Anhui & 1 & Chungchong Nam (8) & 259 & Shikoku & 29 & Vietnam & 12 \\
\hline Beijing & 39 & Chungchong Puk (1) & 112 & Shizuoka & 3 & Yugoslavia & 9 \\
\hline Fujian & 34 & Kangwon (4) & 279 & Tochigi & 4 & Germany & 8 \\
\hline Guangdong & 4 & Kyonggi (7) & 367 & Tohoku (6) & 330 & Algeria & 6 \\
\hline Hebei & 51 & Kyongsang Nam (3) & 256 & Tokyo & 6 & Morocco & 6 \\
\hline Heilongjiang & 136 & Kyongsang Puk (1) & 220 & Yamagata & 2 & Uruguay & 6 \\
\hline Henan & 10 & Pusan & 4 & Unknown (2) & 135 & Belgium & 5 \\
\hline Hubei & 15 & Seoul (1) & 63 & Russian Federation & 220 & India & 5 \\
\hline Hunan & 33 & Unknown (1) & 42 & Amur & 7 & Moldova & 5 \\
\hline Jiangsu $(1)^{\mathrm{a}}$ & 41 & Japan & 1,335 & Far East & 18 & Turkey & 5 \\
\hline Jiangxi (1) & 10 & Akita (4) & 85 & Irkutsk & 2 & Uzbekistan & 5 \\
\hline Jilin (2) & 355 & Chubu & 1 & Khabarovsk & 4 & Hungary & 4 \\
\hline Liaoning & 181 & Fukui & 2 & Krasnodar & 11 & Romania & 4 \\
\hline Nei Mongol & 30 & Fukushima & 5 & Krasnodarsk & 2 & Kazakhstan & 3 \\
\hline Ningxia & 1 & Hokkaido & 137 & NorthOssetia & 5 & Kyrgyzstan & 3 \\
\hline Northeast China (3) & 308 & Hokuriku (1) & 34 & Primorye & 144 & Netherlands & 3 \\
\hline Shaanxi & 17 & Hyogo & 14 & Unknown & 19 & Australia & 2 \\
\hline Shandong & 77 & Iwate & 8 & Korea, North & 132 & Bulgaria & 2 \\
\hline Shanghai & 4 & Kagoshima & 3 & Hamgyong Nam & 1 & Indonesia & 2 \\
\hline Shanxi & 75 & Kanto (1) & 363 & Hamgyong Puk & 48 & Poland & 2 \\
\hline Sichuan (1) & 44 & Kinki & 15 & Kangwon & 6 & Argentina & 1 \\
\hline Tianjin & 1 & Kumamoto (2) & 17 & Pyongan Nam & 6 & CoastRica & 1 \\
\hline Xinjiang & 22 & Kyushu & 44 & Pyongan Puk (1) & 13 & E. Europe & 1 \\
\hline Zhejiang (1) & 31 & Mie & 1 & Pyongyang & 11 & Ireland & 1 \\
\hline Unknown (3) & 546 & Miyagi & 8 & Unknown & 48 & Mexico & 1 \\
\hline Korea, South & 1,947 & Nagano & 8 & UnitedStates & 79 & Peru & 1 \\
\hline Cheju & 3 & Niigata & 1 & Taiwan & 36 & Portugal & 1 \\
\hline Cholla Nam(1) & 191 & Okinawa (1) & 11 & France & 21 & & \\
\hline Cholla Puk & 152 & Saitama & 24 & Georgia & 21 & Unknown & 50 \\
\hline
\end{tabular}

a Number of moderately resistant entries from region indicated in parentheses. 
Table 2. Mean values from sudden death syndrome lesion lengths, foliar ratings, and area under disease progress curve (AUDPC) values for 57 selected soybean plant introductions (PIs) from the USDA Soybean Germplasm inoculated with Fusarium solani f. sp. glycines under greenhouse conditions

\begin{tabular}{|c|c|c|c|c|c|c|c|c|}
\hline \multirow[b]{2}{*}{ Entry } & \multirow[b]{2}{*}{ Cultivar } & \multirow[b]{2}{*}{ Country } & \multirow[b]{2}{*}{ Province } & \multirow[b]{2}{*}{ MG } & \multirow{2}{*}{$\begin{array}{c}\text { Lesion length }{ }^{\mathrm{a}} \\
(\mathrm{mm})\end{array}$} & \multicolumn{2}{|c|}{ Severity ratings $(\%)^{a, b}$} & \multirow[b]{2}{*}{ AUDPC $^{\mathrm{a}, \mathrm{c}}$} \\
\hline & & & & & & 23 day & 30 day & \\
\hline PI243530 & Haiiro & Japan & Akita & IV & 34.4 & 14.7 & 20.6 & 74.1 \\
\hline PI458021 & & Korea, South & Seoul & IV & 35.9 & 15.6 & 20.6 & 92.8 \\
\hline PI423936 & Kyushu 87 & Japan & Kumamoto & III & 28.0 & 18.8 & 21.4 & 92.8 \\
\hline PI243518 & Ao & Japan & Akita & IV & 30.9 & 15.6 & 23.5 & 97.5 \\
\hline PI423740 & & Korea, South & Kyonggi & IV & 36.3 & 16.1 & 23.1 & 103.4 \\
\hline PI088310 & & China & Northeast China & III & 33.8 & 15.3 & 7.6 & 104.6 \\
\hline PI393535 & Aohigu & Japan & Okinawa & III & 34.8 & 15.3 & 21.8 & 107.8 \\
\hline PI082278 & & Korea, South & Unknown & III & 35.5 & 24.1 & 13.8 & 108.8 \\
\hline PI423739 & & Korea, South & Kyonggi & IV & 33.5 & 16.3 & 15.0 & 111.6 \\
\hline PI071850-1 & & China & Northeast China & III & 34.0 & 15.6 & 13.0 & 112.5 \\
\hline FC019979-4 & Sousei O Saya Eda Mame & Japan & Unknown & IV & 33.3 & 17.2 & 13.1 & 113.0 \\
\hline PI424221B & & Korea, South & Kyonggi & IV & 31.0 & 14.7 & 20.0 & 117.2 \\
\hline PI507531 & Waseshu (2) & Japan & Hokuriku & II & 38.8 & 18.8 & 20.8 & 118.6 \\
\hline PI437563 & Bujan'-pin-din-huan & China & Unknown & III & 27.8 & 16.9 & 15.4 & 120.0 \\
\hline PI423813 & & Korea, South & Chungchong Nam & IV & 32.3 & 21.3 & 17.0 & 121.9 \\
\hline PI088823 & Aota & Korea, North & Pyongan Puk & III & 38.2 & 17.2 & 21.4 & 122.4 \\
\hline PI508296B & & Korea, South & Cholla Nam & IV & 32.2 & 17.8 & 23.4 & 127.1 \\
\hline PI059849 & Enoki & Japan & Akita & IV & 34.0 & 17.5 & 7.7 & 128.9 \\
\hline PI423977 & Rikuu 27 & Japan & Akita & IV & 33.2 & 16.6 & 34.1 & 129.9 \\
\hline PI518711 & Jilin 21 & China & Jilin & II & 29.0 & 23.1 & 32.3 & 133.1 \\
\hline PI417482 & Yuumou madara & Japan & Tohoku & III & 34.3 & 20.9 & 22.6 & 134.6 \\
\hline PI423721 & & Korea, South & Kyonggi & IV & 34.0 & 22.5 & 36.8 & 134.6 \\
\hline PI603706A & & China & Jiangxi & IV & 31.6 & 19.1 & 26.6 & 136.4 \\
\hline PI458144 & & Korea, South & Chungchong Nam & IV & 31.4 & 18.4 & 11.8 & 136.9 \\
\hline PI085519 & & Korea, South & Kyonggi & IV & 30.4 & 19.1 & 17.5 & 137.8 \\
\hline PI416748 & & Japan & Tohoku & II & 32.9 & 22.8 & 26.7 & 142.1 \\
\hline PI408109A & & Korea, South & Kyongsang Puk & IV & 35.1 & 24.1 & 16.5 & 146.7 \\
\hline PI399066 & & Korea, South & Chungchong Puk & IV & 35.6 & 26.6 & 38.7 & 147.7 \\
\hline PI507082A & Nanbu & Japan & Tohoku & IV & 35.5 & 25.3 & 22.0 & 148.6 \\
\hline PI398843 & & Korea, South & Chungchong Nam & IV & 34.7 & 26.9 & 31.2 & 150.0 \\
\hline PI423940 & Natsu daizu 1 & Japan & Kumamoto & II & 32.8 & 23.4 & 26.1 & 150.5 \\
\hline PI603753B & & China & Zhejiang & III & 32.0 & 26.3 & 22.6 & 151.9 \\
\hline PI417268 & Sanryuuiri & Japan & Tohoku & II & 34.7 & 21.6 & 24.8 & 152.8 \\
\hline PI085625 & & Korea, South & Kyonggi & II & 32.9 & 22.8 & 10.3 & 155.6 \\
\hline FC019979-1 & Sousei O Saya Eda Mame & Japan & Unknown & IV & 35.3 & 20.6 & 10.6 & 156.1 \\
\hline PI398774 & & Korea, South & Chungchong Nam & IV & 36.8 & 24.4 & 22.5 & 156.6 \\
\hline PI506595A & Bon mame & Japan & Kanto & III & 25.8 & 20.0 & 10.8 & 157.5 \\
\hline PI398790 & & Korea, South & Chungchong Nam & IV & 35.8 & 24.7 & 30.7 & 158.5 \\
\hline PI458095 & & Korea, South & Kangwon & IV & 28.4 & 20.9 & 22.9 & 161.7 \\
\hline PI398720 & & Korea, South & Chungchong Nam & IV & 33.1 & 30.3 & 32.3 & 161.8 \\
\hline PI578505 & Xiao jin huang No. 1 & China & Jilin & II & 30.0 & 26.3 & 28.9 & 161.8 \\
\hline PI437886B & Elita 716 & China & Unknown & II & 29.8 & 20.9 & 17.8 & 164.1 \\
\hline PI507221 & Sennari & Japan & Tohoku & III & 33.8 & 24.4 & 26.3 & 168.8 \\
\hline PI408235 & & Korea, South & Kyongsang Nam & IV & 31.6 & 25.0 & 13.9 & 171.1 \\
\hline PI407655B & & China & Unknown & II & 25.2 & 25.0 & 41.7 & 175.8 \\
\hline PI408309 & & Korea, South & Kyongsang Nam & IV & 29.1 & 24.4 & 26.7 & 178.1 \\
\hline PI408273 & & Korea, South & Kyongsang Nam & IV & 41.5 & 23.1 & 39.1 & 178.2 \\
\hline PI458132 & & Korea, South & Chungchong Nam & IV & 32.0 & 22.5 & 20.2 & 179.1 \\
\hline PI603746 & & China & Sichuan & II & 32.6 & 26.6 & 46.9 & 184.2 \\
\hline PI603690 & & China & Jiangsu & IV & 30.4 & 31.9 & 46.2 & 188.0 \\
\hline PI417195 & Niigata 4 & Japan & Tohoku & IV & 32.3 & 23.4 & 26.1 & 188.5 \\
\hline PI424281A & & Korea, South & Kangwon & IV & 34.8 & 32.8 & 49.2 & 190.8 \\
\hline PI423748B & & Korea, South & Kangwon & IV & 34.2 & 26.3 & 38.1 & 192.2 \\
\hline PI088777 & & China & Northeast China & II & 35.8 & 25.3 & 40.1 & 196.4 \\
\hline PI423816 & & Korea, South & Chungchong Nam & IV & 33.6 & 29.4 & 41.6 & 202.1 \\
\hline PI567280 & & Korea, South & Kangwon & III & 34.2 & 27.5 & 33.2 & 202.5 \\
\hline PI424216 & & Korea, South & Kyonggi & IV & 30.8 & 30.3 & 31.5 & 209.1 \\
\hline CHECK & $\operatorname{GL} 3302(\mathrm{~S})^{\mathrm{d}}$ & & & III & 30.0 & 70.1 & 82.8 & 471.1 \\
\hline CHECK & PI520733 (MR) ${ }^{\mathrm{d}}$ & & & III & 37.2 & 36.6 & 36.8 & 246.9 \\
\hline CHECK & PI567374 (MR) & & & IV & 31.4 & 21.4 & 34.4 & 129.9 \\
\hline $\operatorname{LSD}^{\mathrm{e}}(0.05)$ & & & & & 6.7 & 15.6 & 22.2 & 88.2 \\
\hline
\end{tabular}

a There were eight observations for 23-day severity ratings and AUDPC values and four observations for 30-day severity ratings and lesion length.

${ }^{\mathrm{b}}$ Disease ratings were based on a 1 to 9 scale: $1=$ no symptoms; 2 to $4=$ light symptom development $(1$ to $5 \%, 5$ to $10 \%$, and 10 to $20 \%$ foliage affected); 5 and $6=$ moderate symptom development (20 to $35 \%$ and 35 to $50 \%$ foliage affected); 7 and $8=$ heavy symptom development (50 to $65 \%$ and 65 to $80 \%$ foliage affected); and $9=$ severe symptom development (81 to $100 \%$ foliage affected). Data were converted to midpoint values (5) based on range within each severity rating scale.

c AUDPC value (28) calculated in which $X_{i}=$ the foliar rating at the $i$ th observation, $t_{i}=$ time (days between ratings) at the $i$ th observation, and $\mathrm{n}=$ total number of observations using the midpoint values based on range within each severity rating scale.

d $\mathrm{S}=$ susceptible and MR = moderately resistant.

e LSD = Fisher's protected least significant difference. 


\section{RESULTS}

Plant introductions. Among the 12 subsets of 500 entries initially screened, the mean disease severity rating was 6.0 , compared with ratings of 6.9 for GL3302, 5.2 for PI 520.733, and 4.1 for PI 567.374. Of the 12 subsets, the lowest average rating and AUDPC value were 4.9 and 32.2, respectively, while the highest average rating and AUDPC value were 7.0 and 53.7, respectively. The number of entries taken from each subset ranged from 42 to 189. The mean AUDPC value for all 12 subsets was 44.0, compared with values of 49.8 for GL3302, 38.0 for PI 520.733, and 30.6 for PI 567.374. For the 1,302 entries screened in the second stage, the mean disease severity rating was 6.2 , compared with ratings of 7.3 for GL3302, 5.1 for PI 520.733, and 3.7 for PI 567.374. The mean AUDPC value was 45.4, compared with values of 54.2 for GL3302, 36.1 for PI 520.733, and 29.1 for PI 567.374.

From the replicated stage three experiments (Table 2), 209 of the 212 entries had ratings that were not significantly different from $(P \leq 0.05)$ PI 520.733. However, only 57 of the 212 entries were advanced to the final stage based on foliar symptoms that were not significantly different from $(P \leq$ 0.05) PI 567.374. Because there was no trial by PI interaction $(P=0.11)$, results from the third and final stages were pooled and analyzed together for the 23-day rating and the AUDPC values. The 30-day rating and the root lesion lengths were only measured in the final stage. From the combined replicated experiment, 25 entries had significantly lower $(P \leq 0.05)$ foliar severity ratings and 38 entries had significantly lower AUDPC values than PI 520.733 at 3 weeks after inoculation. None of the entries had lower foliar severity ratings or AUDPC values than PI 567.374. The final experiment was extended 1 week (30 days total) to further test the resistance in the PIs. Eight of the entries had a significantly lower $(P \leq 0.05)$ disease severity rating than PI 520.733, and six entries had a lower rating than PI 567.374. Root lesion length was measured at the same time as the extended rating. Lesion length ranged from 25.2 to $41.5 \mathrm{~mm}$. None of the entries had significantly shorter lesions than the susceptible check GL3302 (30.0 mm). The MR checks, PI 520.733 and PI 567.374, had lesion lengths of 37.2 and $31.4 \mathrm{~mm}$, respectively. Because no PI had shorter lesions than the susceptible check GL3302, resistance from these entries does not appear to be associated with reduced lesion length. The correlation between lesion length and disease foliar severity rating was not significant $(P=0.94$; data not presented).

There also was no plant morphological characteristic associated with higher foliar symptoms. For example, the final foliar ratings of determinate and indeterminate soybean lines were 6.0 and 6.1 , respectively. Also, flower color (purple or white), pubescence color (gray or tawny) or density (normal or semi-sparse), pod color (brown or tan), seed coat luster (dull, shiny, or intermediate), and seed coat color (yellow, black, green, or brown) had aver-

Table 3. Analysis of variance for screening soybean entries with five isolates of Fusarium solani f. sp. glycines

\begin{tabular}{|c|c|c|c|c|}
\hline Source of variation & df & MS & $\boldsymbol{F}$ & $P>F$ \\
\hline \multicolumn{5}{|c|}{ Isolate study (final rating) ${ }^{\mathrm{a}}$} \\
\hline Trial & 1 & $2,223.29$ & 9.70 & 0.0020 \\
\hline Block (trial) & 4 & 634.98 & 2.77 & 0.0270 \\
\hline Isolate & 4 & $24,109.62$ & 105.21 & 0.0001 \\
\hline Entry & 20 & $4,212.65$ & 18.38 & 0.0001 \\
\hline Isolate $\times$ trial & 4 & 499.58 & 2.18 & 0.0907 \\
\hline Entry $\times$ trial & 20 & 349.01 & 1.52 & 0.0694 \\
\hline Entry $\times$ isolate & 80 & 198.49 & 0.87 & 0.7819 \\
\hline Entry $\times$ isolate $\times$ trial & 80 & 157.07 & 0.69 & 0.9800 \\
\hline \multicolumn{5}{|c|}{ Isolate study (AUDPC value) ${ }^{\mathrm{a}}$} \\
\hline Trial & 1 & $492,107.27$ & 27.38 & 0.0001 \\
\hline Block (trial) & 4 & $15,117.54$ & 0.84 & 0.4997 \\
\hline Isolate & 4 & $1,762,725.68$ & 98.06 & 0.0001 \\
\hline Entry & 20 & $298,639.61$ & 16.61 & 0.0001 \\
\hline Isolate $\times$ trial & 4 & $46,198.53$ & 2.57 & 0.0723 \\
\hline Entry $\times$ trial & 20 & $11,812.85$ & 0.66 & 0.8679 \\
\hline Entry $\times$ isolate & 80 & $20,917.09$ & 1.16 & 0.1761 \\
\hline Entry $\times$ isolate $\times$ trial & 80 & $12,396.84$ & 0.69 & 0.9784 \\
\hline \multicolumn{5}{|c|}{ Isolate study (lesion lengtha ${ }^{\mathrm{a}}$} \\
\hline Trial & 1 & 25.62 & 0.40 & 0.5298 \\
\hline Block (trial) & 2 & 821.54 & 12.70 & 0.0001 \\
\hline Isolate & 4 & 867.89 & 13.42 & 0.0001 \\
\hline Entry & 20 & 120.96 & 1.87 & 0.0227 \\
\hline Isolate $\times$ trial & 4 & 2.20 & 0.03 & 0.9978 \\
\hline Entry $\times$ trial & 20 & 6.60 & 0.10 & 1.0000 \\
\hline Entry $\times$ isolate & 80 & 70.05 & 1.08 & 0.3236 \\
\hline Entry $\times$ isolate $\times$ trial & 80 & 6.03 & 0.09 & 1.0000 \\
\hline
\end{tabular}

${ }^{a}$ In this study, 18 plant introductions and three checks were arranged in a randomized complete block design with three blocks. The experiment was repeated. age foliar ratings between 5.9 and 6.2 and were not statistically different.

Isolate study. There were no significant entry or isolate by trial interactions (Table $3)$; therefore data from each trial were pooled and analyzed together. Differences in ability to cause foliar symptoms among isolates were significant $(P<0.01)$; isolate Mont-1 caused the most disease (Table 4). No entries had foliar ratings significantly different from PI 520.733 except for PI 88.823 when inoculated with isolates Mont-1 and 98-7, and PI 423.813 when inoculated with isolate FSA-1. However, all the entries had foliar severity ratings and AUDPC values significantly lower than the susceptible check GL3302. For the root lesion length, there were significant differences among soybean entries $(P=$ $0.02)$ and isolates $(P<0.01)$. PI 82.278 had the shortest mean lesion length (31.0 $\mathrm{mm})$, and PI 423.739 had the longest mean lesion length (42.4 mm). GL3302 roots had lesion lengths ranging from 28.7 to 35.9 $\mathrm{mm}$ from the different isolates. Lesion lengths for PI 567.374 and PI 520.733 ranged from 32.4 to $45.5 \mathrm{~mm}$ and 34.2 to $47.4 \mathrm{~mm}$, respectively. Isolate $\mathrm{BH}-\mathrm{F} 2-13$ had the longest mean lesion length (41.6 $\mathrm{mm})$, while isolates FSA-1 and 98-7 had the shortest mean lesion length $(33.6 \mathrm{~mm})$. Isolates Mont-1 and In had mean lesion lengths of 36.5 and $37.0 \mathrm{~mm}$, respectively.

\section{DISCUSSION}

Plant introductions have been screened extensively for sources of resistance to other important soybean diseases, such as brown stem rot $(1,2)$, Phytophthora root rot (15), soybean cyst nematode $(6,7,31)$, and Sclerotinia stem rot (D. D. Hoffman, B. W. Diers, G. L. Hartman, C. D. Nickell, R. L. Nelson, W. L. Pedersen, E. R. Cober, A. E. Dorrance, G. L. Graef, J. R. Steadman, C. R. Grau, B. D. Nelson, L. E. del Rio, V. Poysa, I. Rajcan, T. Helms, and W. C. Stienstra, unpublished; 12). PIs have been identified with resistance to these diseases. A prior evaluation of sudden death syndrome resistance in the Chinese germ plasm (10) identified several PIs with higher levels of resistance than the MR check PI 520.733.

This evaluation of soybean germ plasm included testing 6,037 soybean entries from 38 countries. Of the 57 entries selected from the final screening, 27 originated from South Korea, 17 from Japan, 12 from China, and 1 from North Korea. Eleven entries were maturity group (MG) II, 12 were MG III, and 34 were MG IV. Chungchong Nam (South Korea) and Kyonggi (South Korea) both contributed eight and seven entries to the 57 most resistant lines. Tohoku (Japan), Akita (Japan), and Kangwon (South Korea) contributed six, four, and four entries, respectively. No other province contributed more than three entries to the most resistant lines. To date, sudden death syndrome 
has not been reported in any of these countries.

Plant morphological characteristics sometimes are associated with disease resistance. For example, pubescence was shown to be a resistance mechanism of soybean for beet armyworm feeding (27) and spread of soybean mosaic virus (22), while traits like hypocotyl color $(18,20)$, seed coat color $(3,6,21)$, and plant height (D. D. Hoffman, B. W. Diers, G. L. Hartman, C. D. Nickell, R. L. Nelson, W. L. Pedersen, E. R. Cober, A. E. Dorrance, G. L. Graef, J. R. Steadman, C. R. Grau, B. D. Nelson, L. E. del Rio, V. Poysa, I. Rajcan, T. Helms, and W. C. Stienstra, unpublished; 12) were found to be associated with resistance to various diseases of soybean and bean (Phaseolus vulgaris L.). In this study, there was no relationship between the level of resistance to sudden death syndrome and morphological characteristics such as stem termination, flower color, pubescence color or density, seed coat luster, and pod, seed, or hilum color.

It is important that the new sources of resistance to sudden death syndrome are effective against isolates of $F$. solani $\mathrm{f}$. sp. glycines from geographically diverse areas. Using five isolates, all 18 of the moderately resistant PIs were classified as moderately resistant with a few excep- tions. There were differences in the amount of foliar symptoms that each of the isolates caused. The ability of isolates to cause differing levels of disease has been noted $(9,19,26)$. For example, Mont1 was reported to be one of the more aggressive isolates (9). The existence of races of $F$. solani f. sp. glycines has been suggested from preliminary data (17), but there have been no additional reports indicating this. In our research, there was no significant interaction among the five isolates tested on the 18 moderately resistant PIs.

The main objective of this test was to identify the best sources of resistance to sudden death syndrome in this set of PIs and provide this material to a soybeanbreeding program. In this test, we eliminated 5,825 PIs using only the Mont-1 isolate known to be highly aggressive and nonreplicate screens. There may still be PIs discarded in our test that could have usable resistance to Fusarium solani f. sp. glycines. The 57 PIs found to be MR to sudden death syndrome may be used as new sources of resistance to increase the level of resistance in U.S. cultivars. In a previous greenhouse screen of 1,670 current cultivars, over $98 \%$ were classified as susceptible (data available at the Varietal Information Program for Soybeans [VIPS] website).
ACKNOWLEDGMENTS

Salaries and research support provided in part by the Illinois Soybean Program Operating Board (ISPOB). We thank K. Ames, C. Bradley, M. Gardner, C. Leman, J. Mueller, R. Warsaw, and C. Weeks for their assistance.

\section{LITERATURE CITED}

1. Bachman, M. S., and Nickell, C. D. 2000. High frequency of brown stem rot resistance in soybean germ plasm from central and southern China. Plant Dis. 84:694-699.

2. Bachman, M. S., Nickell, C. D., Stephens, P. A., and Nickell, A. D. 1997. Brown stem rot resistance in soybean germ plasm from central China. Plant Dis. 81:953-956.

3. Beebe, S. E., Bliss, F. A., and Schwartz, H. F. 1981. Root rot resistance in common bean germ plasm of Latin American origin. Plant Dis. 65:485-489.

4. Booth, C. 1971. The genus Fusarium. Commonwealth Mycological Institute, Kew, England.

5. Campbell, C. L., and Madden, L. V. 1990. Introduction to Plant Epidemiology. John Wiley \& Sons, New York.

6. Caviness, C. E. 1992. Breeding for resistance to soybean cyst nematode. Pages 143-156 in: Biology \& Management of the Soybean Cyst Nematode. R. D. Riggs and J. Wrather, eds. American Phytopathological Society, St. Paul, MN.

7. Davis, E. L., Koenning, S. R., Burton, J. W., and Barker, K. R. 1996. Greenhouse evaluation of selected soybean germplasm for resistance to North Carolina populations of Herterodera glycines, Rotylenchulus reniformis, and Meloidogyne species. J. Nematol. 28:590-598.

Table 4. Rating means of foliar symptoms and area under disease progress curve (AUDPC) of 21 selected soybean entries inoculated with five isolates of Fusarium solani f. sp. glycines under greenhouse conditions

\begin{tabular}{|c|c|c|c|c|c|c|c|c|c|c|}
\hline \multirow[b]{2}{*}{ Entry } & \multicolumn{2}{|c|}{ Mont-1 ${ }^{a}$} & \multicolumn{2}{|c|}{$\operatorname{In}^{\mathrm{a}}$} & \multicolumn{2}{|c|}{ BH-F2-13a } & \multicolumn{2}{|c|}{ FSA-1 ${ }^{a}$} & \multicolumn{2}{|c|}{$98-7^{a}$} \\
\hline & Rating $^{\mathbf{b}, \mathbf{c}}$ & $\mathrm{AUDPC}^{\mathrm{c}, \mathrm{d}}$ & Rating & AUDPC & Rating & AUDPC & Rating & AUDPC & Rating & AUDPC \\
\hline FC 119.979-4 & 27.1 & 225.0 & 3.3 & 38.2 & 5.0 & 20.0 & 2.5 & 11.3 & 6.3 & 18.8 \\
\hline PI 59.849 & 40.4 & 236.9 & 6.3 & 66.9 & 3.8 & 23.2 & 5.8 & 53.1 & 2.1 & 8.2 \\
\hline PI 71.850-1 & 38.8 & 348.8 & 16.3 & 119.4 & 8.8 & 31.9 & 5.4 & 26.9 & 20.0 & 86.9 \\
\hline PI 82.278 & 60.0 & 267.6 & 24.6 & 118.2 & 10.4 & 28.2 & 22.0 & 73.2 & 11.7 & 25.0 \\
\hline PI 88.310 & 42.9 & 286.9 & 15.4 & 125.6 & 8.3 & 35.0 & 9.6 & 73.2 & 15.4 & 102.5 \\
\hline PI 88.823 & 68.8 & 650.0 & 13.8 & 139.4 & 7.5 & 58.8 & 16.7 & 95.0 & 21.7 & 100.1 \\
\hline PI 243.518 & 38.3 & 235.0 & 17.1 & 106.9 & 6.3 & 29.4 & 9.2 & 42.5 & 16.3 & 76.9 \\
\hline PI 243.530 & 32.5 & 254.4 & 7.9 & 46.9 & 1.3 & 6.9 & 3.8 & 39.3 & 2.1 & 5.7 \\
\hline PI 393.535 & 35.0 & 290.7 & 16.3 & 109.4 & 6.7 & 31.3 & 2.1 & 20.7 & 14.2 & 62.5 \\
\hline PI 423.739 & 34.6 & 328.8 & 12.5 & 92.5 & 1.3 & 16.3 & 10.4 & 83.2 & 4.6 & 16.9 \\
\hline PI 423.740 & 27.9 & 220.0 & 9.2 & 88.8 & 4.2 & 17.5 & 6.3 & 21.9 & 5.0 & 25.0 \\
\hline PI 423.813 & 41.7 & 326.3 & 15.0 & 101.3 & 7.5 & 28.8 & 30.4 & 134.4 & 15.8 & 52.5 \\
\hline PI 423.936 & 38.3 & 248.8 & 5.0 & 27.5 & 5.4 & 24.4 & 13.8 & 68.2 & 13.8 & 41.9 \\
\hline PI 424.221B & 40.0 & 330.0 & 11.3 & 109.4 & 4.6 & 16.9 & 4.6 & 36.9 & 4.6 & 14.4 \\
\hline PI 437.563 & 45.4 & 381.3 & 6.7 & 43.2 & 5.8 & 30.0 & 2.9 & 20.0 & 12.9 & 85.0 \\
\hline PI 458.021 & 32.1 & 221.9 & 11.3 & 73.2 & 7.1 & 29.4 & 3.3 & 30.0 & 5.8 & 16.3 \\
\hline PI 458.144 & 42.9 & 389.4 & 18.8 & 160.0 & 6.8 & 44.0 & 8.8 & 86.9 & 16.7 & 61.3 \\
\hline PI 507.531 & 30.0 & 275.1 & 10.4 & 93.8 & 1.3 & 14.4 & 5.8 & 42.5 & 11.3 & 74.4 \\
\hline GL3302 (S) $)^{\mathrm{e}}$ & 87.1 & 957.6 & 68.3 & 583.2 & 60.4 & 515.7 & 47.1 & 284.4 & 54.6 & 293.8 \\
\hline PI $520.733(\mathrm{MR})^{\mathrm{e}}$ & 52.5 & 300.7 & 3.8 & 43.8 & 3.8 & 28.1 & 3.8 & 17.5 & 4.6 & 20.7 \\
\hline PI 567.374 (MR) & 16.7 & 121.3 & 2.1 & 12.5 & 1.7 & 3.1 & 0.4 & 7.5 & 1.3 & 3.1 \\
\hline Mean $^{\mathrm{f}}$ & 41.6 & 328.4 & 14.0 & 109.5 & 8.0 & 49.2 & 10.2 & 60.4 & 12.4 & 56.8 \\
\hline $\operatorname{LSD}^{g}(0.05)$ & 19.8 & 211.2 & 17.0 & 146.1 & 8.5 & 92.4 & 12.8 & 80.3 & 15.4 & 79.3 \\
\hline
\end{tabular}

a Isolate Mont-1 (P. Stevens, Illinois); In (S. Abney, Indiana); BH-F2-13 (X. Yang, Iowa); FSA-1 (J. Rupe, Arkansas); $98-7$ (S. Li, Illinois).

b Disease ratings were based on a 1 to 9 scale: $1=$ no symptoms; 2 to $4=$ light symptom development $(1$ to $5 \%, 5$ to $10 \%$, and 10 to $20 \%$ foliage affected); 5 and $6=$ moderate symptom development ( 20 to $35 \%$ and 35 to $50 \%$ foliage affected); 7 and $8=$ heavy symptom development (50 to $65 \%$ and 65 to $80 \%$ foliage affected); and $9=$ severe symptom development (81 to $100 \%$ foliage affected). Data were converted to midpoint values (5) based on range within each severity rating scale.

c There were six observations for severity ratings and AUDPC values.

${ }^{\mathrm{d}}$ AUDPC value (29) calculated in which $X_{i}=$ the foliar rating at the $i$ th observation, $t_{i}=$ time (days between ratings) at the $i$ th observation, and $\mathrm{n}=$ total number of observations.

e $\mathrm{S}=$ susceptible and $\mathrm{MR}=$ moderately resistant.

${ }^{\mathrm{f}} \mathrm{LSD}(0.05)$ values for comparing means of isolates are 3.7 for rating and 32.1 for AUDPC values.

g LSD = Fisher's protected least significant difference. 
8. Doupnik, B., Jr. 1993. Soybean production and disease loss estimates for North Central United States from 1989 to 1991. Plant Dis. 77:1170-1171.

9. Gray, L. E., and Achenbach, L. A. 1996. Severity of foliar symptoms and root and crown rot of soybean inoculated with various isolates and inoculum rates of Fusarium solani. Plant Dis. 80:1197-1199.

10. Hartman, G. L., Huang, Y. H., Nelson, R. L., and Noel, G. R. 1997. Germplasm evaluation of Glycine max for resistance to Fusarium solani, the causal organism of sudden death syndrome. Plant Dis. 81:515-518.

11. Hartman, G. L., Noel, G. R., and Gray, L. E. 1995. Occurrence of soybean sudden death syndrome in east-central Illinois and associated yield losses. Plant Dis. 79:314-318.

12. Hoffman, D. D. 2001. Genetic analysis of the resistance of soybean genotypes of Sclerotinia sclerotiorum. Ph.D. diss. University of Illinois, Urbana-Champaign.

13. Huang, Y. H., and Hartman, G. L. 1998. Reaction of selected soybean genotypes to isolates of Fusarium solani f. sp. glycines and their culture filtrates. Plant Dis. 82:999-1002.

14. Killebrew, J. F., Roy, K. W., Lawrence, G. W., McLean, K. S., and Hodges, H. H. 1988. Greenhouse and field evaluation of Fusarium solani pathogenicity to soybean seedlings. Plant Dis. 72:1067-1070.

15. Kyle, D. E., Nickell, C. D., Nelson, R. L., and Pedersen, W. L. 1998. Response of soybean accessions from provinces in southern China to Phytophthora sojae. Plant Dis. 82:555-559.

16. Li, S., Hartman, G. L., and Widholm, J. M. 1999. Viability staining of soybean suspension-cultured cells and a seedling stem cutting assay to evaluate phytotoxicity of Fusarium solani f. sp. glycines filtrates. Plant Cell Rep. 18:375-380.

17. Lim, S. M., and Jin, H. 1991. Pathogenic variability in Fusarium solani isolated from soybeans with sudden death syndrome symptoms. (Abstr.) Phytopathology 81:1236.

18. McLean, D. M., Hoffman, J. C., and Brown, G. B. 1968. Greenhouse studies on resistance of snap beans to Rhizoctonia solani. Plant Dis. Rep. 52:486-488.

19. Melgar, J., and Roy, K. W. 1994. Soybean sudden death syndrome: Cultivar reactions to inoculation in a controlled environment and host range and virulence of causal agent. Plant Dis. 78:265-268.

20. Moody, A. R., Benepal, P. S., and Berkley, B. 1980. Resistance of Phaseolus vulgaris L. cultivars to hypocotyl inoculation with Rhizoctonia solani Kuehn. J. Am. Hortic. Sci. 105:836-838.

21. Prasad, K., and Weigle, J. L. 1976. Association of seed coat factors with resistance to Rhizoctonia solani in Phaseolus vulgaris. Phytopathology 66:342-345.

22. Ren, Q., Pfeiffer, T. W., and Ghabrial, S. A. 2000. Relationship between soybean pubescence density and soybean mosaic virus field spread. Euphytica 111:191-198.

23. Roy, K. W. 1997. Fusarium solani on soybean roots: Nomenclature of the causal agent of sudden death syndrome and identity and relevance of F. solani form B. Plant Dis. 81:259-266.

24. Roy, K. W., Rupe, J. C., Hershman, D. E., and Abney, T. S. 1997. Sudden death syndrome of soybean. Plant Dis. 81:1100-1111.

25. Rupe, J. C. 1987. Occurrence and pathogenicity of Fusarium solani recovered from soybeans with sudden death syndrome. (Abstr.) Phytopathology 77:1689.

26. Rupe, J. C. 1989. Frequency and pathogenicity of Fusarium solani recovered from soybeans with sudden death syndrome. Plant Dis. 73:581-584.

27. Tillman, P. G., Lambert, L., and Mulrooney, J. E. 1997. Influence of soybean pubescence on abundance of beet armyworm, Spodoptera exigua. Southwest. Entomol. 22:459-460.

28. Tooley, P. W., and Grau, C. R. 1984. Field characterization of rate-reducing resistance to Phytophthora megasperma f. sp. glycinea in soybean. Phytopathology 74:1201-1208.

29. Wrather, J. A., Anderson, T. R., Arsyad, D. M., Gai, J., Ploper, L. D., Porta-Puglia, A. Ram, H. H., and Yorinori, J. T. 1997. Soybean disease loss estimates for the top 10 soybean producing countries in 1994. Plant Dis 81:107-110.

30. Yang, X. B., and Lundeen, P. 1997. Occurrence and distribution of soybean sudden death syndrome in Iowa. Plant Dis. 81:719-722.

31. Young, L. D. 1995. Soybean germplasm resistant to races 3,5 , or 14 of soybean cyst nematode. Crop Sci. 35:895-896. 